\title{
Examining the predictive role of self-compassion on flourishing in Turkish university students
}

\author{
Ahmet Akin*, and Umran Akin
}

Sakarya University, Faculty of Education, Department of Psychological Counselling and Guidance, Sakarya (Turkey).

\begin{abstract}
Título: Examen del papel predictivo de la autocompasión sobre el bienestar psicológico (flourishing) en estudiantes universitarios de Turquía.

Resumen: El propósito de este estudio es examinar el papel predictivo de la autocompasión sobre el flourishing. Los participantes fueron 278 estudiantes universitarios (153 mujeres, 125 hombres; edad media $=20.5$ años) En este estudio, la Escala de Autocompasión y la escala de Flourishing fueron examinadas usando análisis correlacional y análisis de regresión lineal múltiple. En el análisis correlacional, los factores de auto-benevolencia, condición humana y atención plena de la autocompasión tuvieron relación positiva con el flourishing, y auto-valoración, aislamiento y sobreidentificación tuvieron relación negativa. Según los resultados de regresión, flourishing fue predicho negativamente por la auto-valoración, el aislamiento y la sobre-identificación. Además, la auto-benevolencia y la atención plena predicen el flourishing de modo positivo. La autocompasión explicó el $47 \%$ de la varianza del flourishing. Los resultados se discuten a la luz de la literatura.

Palabras clave: Autocompasión, bienestar psicológico, regresión lineal múltiple.
\end{abstract}

\section{Self-compassion}

Self-compassion involves to treat gentle towards oneself in difficult times and requires acknowledging that pain, failure, and inadequacies are part of the human condition and that all individuals, oneself included, are worthy of compassion (Neff, 2003b; Neff, Kirkpatrick, \& Rude, 2007). As described by Neff (2003a, b) self-compassion is a threedimensional construct: (a) Self-kindness vs. self-judgment (b) Awareness of common humanity vs. isolation, and (c) Mindfulness vs. over-identification. Self-kindness refers to being kind and understanding toward oneself in instances of negative experiences rather than being harshly self-critical. If people with self-kindness notice some unfavorable features of their personality they use a soft and supportive emotional tone of language towards themselves (Neff, 2009). Awareness of common humanity means that an individual perceives both happy and painful experiences as not personal, but as all human beings'. It implies recognizing that all humans are imperfect and that they fail (Neff, 2009). Having this kind of awareness, an individual perceives these negative experiences as part of the larger human experience rather than feeling isolated from the society (Neff, 2003a).

Mindfulness is a pre-conceptual awareness that helps people to accept most distressful and painful emotions without being carried away by them (Gunaratana, 1993; Martin, 1997; Neff, 2003a; Nisker, 1998; Rosenberg, 1999). As a mindful approach to the life events prevents habitual reacting and encourages a more adaptive deliberate response to

* Dirección para correspondencia [Correspondence address]: Ahmet Akin. Sakarya University, Faculty of Education 54300 Hendek/Sakarya (Turkey).E-mail: aakin@sakarya.edu.tr
Abstract: The purpose of this study is to examine the predictive role of self-compassion on flourishing. Participants were 278 university students (153 women, 125 men). In this study, the Self-compassion Scale and the Flourishing Scale were used. The relationships between self-compassion and flourishing were examined using correlation and regression analysis. In correlation analysis, self-kindness, common humanity, and mindfulness factors of self-compassion were found positively and self-judgment, isolation, and over-identification factors of self-compassion were found negatively related to flourishing. According to regression results, flourishing was predicted negatively by self-judgment, isolation, and over-identification. Further self-kindness and mindfulness predicted flourishing in a positive way. Self-compassion has explained $47 \%$ of the variance in flourishing. Results were discussed in the light of related literature.

Keywords: Self-compassion, flourishing, regression.

experiences (Baer, Smith, \& Allen, 2004), mindfulness-based interventions are believed to enhance affective balance and psychological well-being (Schroevers \& Brandsma, 2010). For example Mindfulness-Based Stress Reduction intervention has been shown to lower perceived stress and rumination in non-clinical undergraduates (Shapiro, Oman, Thoresen, Plante, \& Flinders, 2008) while Mindfulness-Based Cognitive Therapy (Segal, Williams, \& Teasdale, 2002) has been shown to reduce the relapse of major depression better than ordinary treatments alone.

Numerous studies demonstrated that self-compassion is a strong and significant indicator of psychological health in a variety of domains such as affect, cognitive patterns, achievement, and social connections. In these research it was found that self-compassion is linked positively to social relationship, emotional intelligence, self-determination (Neff, 2003a), social support (Akın, Kayıs, \& Satıc1, 2011), psychological well-being (Akin, 2008a), learning-approach goals (Akin, 2008b), life satisfaction, social relatedness (Neff, 2003b), reflective and affective wisdom, personal initiative, curiosity and exploration, optimism, positive affect, extraversion, agreeableness, conscientiousness (Baker \& McNulty, 2011; Neff, Rude, \& Kirkpatrick, 2007), and relational-interdependent self-construal (Akın \& Eroglu, 2013). Conversely, the other studies have showed that selfcompassion is negatively related to interpersonal cognitive distortions (Akın, 2010a), loneliness (Akın, 2010b), submissive behavior (Akın, 2009), automatic thoughts (Akın, 2012), depression, anxiety, rumination, thought suppression (Neff, 2003b), performance-approach/avoidance goals (Akin, 2008b), internet addiction (Iskender \& Akin, 2011), social anxiety, fear of negative evaluation (Werner et al., 2012), and neuroticism (Neff, Rude, \& Kirkpatrick, 2007). 


\section{Flourishing}

Flourishing, a form of positive mental health, is described as living within an optimal range of human functioning, generativity, performance, and growth (Fredrickson \& Losada, 2005; Larsen \& Prizmic, 2008) and is characterized by "doing and living well" rather than "feeling good" (Forgeard, Jayawickreme, Kern, \& Seligman, 2011). Having a balance of positive to negative affect is also a key factor in defining whether a person flourishes (Diehl, Hay, \& Berg, 2011) and thus flourishing is different from the absence of mental illness (Keyes, 2005, 2007; Michalec, Keyes, \& Nalkur, 2009). Seligman (2011) suggested five elements of flourishing which are summarized in the acronym PERMA; positive emotions, engagement, relationships, meaning, and achievement. Flourishing is the capacity to experience any one of these five components as a means to enhance, deepen, and expand one's life (Ramones, 2011).

Research on flourishing has consistently demonstrated that high level of flourishing is positively related to psychological, social, and cognitive well-being (Keyes, 2002). In these studies it was found that flourishing associated positively with emotional vitality (Michalec et al., 2009), positive emotions, life satisfaction, resiliency, autonomy, productivity, competency, personal adjustment and development (Diehl et al., 2011; Diener et al., 2010; Keyes, 2002; Telef, 2011), self-acceptance (Diener et al., 2010), mindfulness, and positive emotional reactivity (Catalino \& Fredrickson, 2011) and negatively to depression (Keyes, 2002), mental illness (Michalec et al., 2009), and negative affect (Diehl et al., 2011; Keyes, 2002). Also studies suggest that individuals with a sense of flourishing are more likely to contribute to their communities (Huppert, 2009; Michalec et al., 2009), are more productive at work, enjoy better social relationships, experience less limitations on daily activities (Huppert, 2009; Keyes, 2005), have higher levels of environmental control, positive relations with others (Telef, 2011), and relatedness, lower levels of loneliness (Diener et al., 2010; Gokcen, Hefferon, \& Attree, 2012). Moreover, other studies have showed the correlations of flourishing with indicators of cognitive well-being such as perceiving that life is going well (Huppert \& So, 2009), realizing potentials in different aspects of life and trying to achieve (Gokcen et al., 2012), and better life expectancy and life purpose (Huppert, 2009; Keyes, 2005; Telef, 2011).

\section{The present study}

Although numerous research conducted with the selfcompassion is encouraging, to date, however, relatively few research has examined the role of self-compassion on positive mental health indicators. Therefore the goal of the present research is to investigate the predictive role of selfcompassion on flourishing on a sample of university students. Previous evidence suggests that both self-compassion and flourishing are strongly and positively related to psycho- logical well-being and positive emotions (Akın, 2008a; Keyes, 2002; Michalec et al., 2009; Seligman, 2011) and inversely related to loneliness (Akın, 2010b; Diener et al., 2010) and depression (Keyes, 2005; Neff, 2003b). Also, selfkindness, common humanity, and mindfulness, adaptive dimension of self-compassion, allow people to feel cared for, connected, and emotionally calm, remedy reactions to negative experiences, and buffer people against the influence of negative self-feelings and distressful experiences (Leary, Tate, Adams, Allen, \& Hancock, 2007) and thus enhances well-being (Gilbert, 2005). Therefore there may be a linear positive relationship between self-compassion and flourishing. Based on the above relationships of self-compassion and flourishing, in the current study it was hypothesized that self-kindness, common humanity, and mindfulness, adaptive dimensions of self-compassion, would be associated positively and self-judgment, isolation, and over-identification, maladaptive dimensions of self-compassion, would be associated negatively with flourishing.

\section{Method}

\section{Participants}

Participants were 278 university students (153 women, 125 men) enrolled in various undergraduate programs at Sakarya and Kocaeli Universities, Turkey. These programs were psychological counselling and guidance $(n=60)$, Turkish education $(n=53)$, science education $(n=65)$, computer and instructional technology education $(n=56)$, and pre-school education $(n=44)$. Of the participants, 53 were first-year students, 85 were second-year students, 68 were third-year students, and 72 were fourth-year student. Their ages ranged from 18 to 31 years old and grade point average scores ranged from 1.77 to 3.81 .

\section{Measures}

Self-compassion Scale. Self-compassion was measured by using Self-compassion Scale (Neff, 2003b). Turkish adaptation of this scale had been done by Akın, Akın, and Abac1 (2007). Self-compassion Scale is a 26-item self-report measurement and consists of six sub-scales; self-kindness (five items, e. g., I try to be loving towards myself when I'm feeling emotional pain.), self-judgment (five items, e. g., When times are really difficult, I tend to be tough on myself.), common humanity (four items, e. g., I try to see my failings as part of the human condition.), isolation (four items, e. g., When I fail at something that's important to me, I tend to feel alone in my failure.), mindfulness (four items, e. g., When something upsets me I try to keep my emotions in balance.), and overidentification (four items, e. g., When I'm feeling down I tend to obsess and fixate on everything that's wrong.). Each item was rated on a 5 -point Likert scale $(1=$ strongly disagree to $5=$ strongly agree). Results of language equivalence study with a sample of 135 English teachers indicated that correlations 
between Turkish and English forms were .94, .94, .87, .89, .92 , and .94 for six subscales, respectively. The goodness of fit indexes from confirmatory factor analysis were: $x^{2}=$ 779.01, $\mathrm{df}=264, \mathrm{RMSEA}=.056, \mathrm{NFI}=.95, \mathrm{CFI}=.97, \mathrm{IFI}=$ $.97, \mathrm{RFI}=.94, \mathrm{GFI}=.91$, and $\mathrm{SRMR}=.059$. The internal consistency coefficients were $.77, .72, .72, .80, .74$, and .74 and the test-retest reliability coefficients were $.69, .59, .66$, .60 .69 , and .56, for six subscales, respectively.

Flourishing Scale (Diener et al., 2010). The scale consist of 8 items (e.g., I am competent and capable in the activities that are important to me) and each item is answered on a 17 scale that ranges from strong disagreement to strong agreement. A sum of all score yields a total score ranges from 8 to 56 and higher score indicated that respondents view themselves in positive terms in important areas of functioning. Turkish adaptation of this scale had been done by Akin and Fidan (2012). The internal consistency coefficient of the scale was .83 and the corrected item-total correlations ranged from .47 to .67 . The goodness of fit indexes from confirmatory factor analysis were: $x^{2}=48.80, \mathrm{df}=18$, RMSEA $=.066, \mathrm{NFI}=.97, \mathrm{CFI}=.98, \mathrm{IFI}=.98, \mathrm{RFI}=.96$, $\mathrm{GFI}=.97$, and $\mathrm{SRMR}=.038$. Factor loadings ranged from .60 to .78 .

\section{Procedure}

The study was predictive, non-experimental survey design in nature, quantitative research and was designed to gather data concerning the relationship between selfcompassion and flourishing. Data were collected from selfreport scales. Permission for participation of students was obtained from related chief departments and students voluntarily participated in research. Participants were told about the nature of the study and they were also assured that information provided by them would be kept confidential and would be used only for the research purpose. The instructions related to filling out the forms were given and they were asked to mark each and every item without leaving any item unanswered. Participants have not been rewarded in any manner to fill out the scales and none of the students declined the participation. For every participants, the order of administration of the scales was changed to control order effect. Self-compassion Scale, Flourishing Scale, and a form which contains information on participants' gender, age, level of education, grade point average, and department were administered to the students in groups in the classrooms.

\section{Statistical Analysis}

Two hundred and ninety-three students participated in the study. However, 15 students were excluded from the study because 7 of them did not respond to the instruments as required and 8 were found to produce extreme scores. Therefore, the data obtained from 278 students were statistically analyzed. In this research, regression analysis and Pearson correlation coefficient were used to investigate the relationships between self-compassion and flourishing. The variables which were entered in regression analysis were measured by summing the items of each scale. These analyses were carried out via SPSS 11.5.

\section{Results}

\section{Descriptive Data and Inter-correlations}

Table 1 shows the means, standard deviations, intercorrelations, and internal consistency coefficients of the variables used.

Table 1. Descriptive Statistics, Alphas, and Inter-correlations of the Variables

\begin{tabular}{llllllll}
\hline Variables & 1 & 2 & 3 & 4 & 5 & 6 & 7 \\
\hline 1. Self-kindness & - & & & & & & \\
2. Self-judgment & $-.46^{* *}-$ & & & & & \\
3. Com. humanity & $.48^{* *}$ & $-.30^{* *}-$ & & & & \\
4. Isolation & $-.44^{* *}$ & $.74^{* *}$ & $-.23^{* *}$ & - & & & \\
5. Mindfulness & $.69^{* *}$ & $-.49^{* *}$ & $.48^{* *}$ & $-.42^{* *}-$ & & \\
6. Over-iden. & $-.39^{* *}$ & $.66^{* *}$ & $-.23^{* *}$ & $.57^{* *}$ & $-.42^{* *}-$ & - & \\
7. Flourishing & $.57^{* *}$ & $-.55^{* *}$ & $.33^{* *}$ & $-.52^{* *}$ & $.54^{* *}$ & $-.49^{* *}$ & \\
Mean & 14.22 & 12.02 & 11.29 & 10.63 & 11.87 & 10.74 & 43.17 \\
SD & 4.63 & 5.01 & 3.50 & 4.40 & 3.88 & 4.45 & 8.02 \\
Cronbach's $a$ & .75 & .60 & .72 & .73 & .85 & .74 & .80 \\
\hline$* * p<.01$ & & & & & & &
\end{tabular}

Table 1 shows descriptive statistics and correlations among the variables. Self-kindness $(r=.57, p<.01)$, common humanity $(r=.33, p<.05)$, and mindfulness $(r=.54, p<.01)$ were found positively and self-judgment $(r=-.55, p<.01)$, isolation $(r=-.52, p<.01)$, and over-identification $(r=-.49$, $p<.01)$ were found negatively associated with flourishing. There were also significant correlations between dimensions of self-compassion.

\section{Regression Analysis}

Before applying regression, assumptions of regression were checked. In order to run parametric tests the data were examined for normality by the Kolmogorov-Smirnov test. The Kolmogorov-Smirnov test indicated normality of distributions of test scores for all tests in the current study. Hierarchical regression analysis was performed in which the dependent variable was flourishing and the independent variables were dimensions of self-compassion (Table 2).

According to the results of regression analysis, summarized in Table 2, self- kindness entered the equation first, accounting for $33 \%$ of the variance in predicting flourishing $\left(R^{2}=.33\right.$, adjusted $\left.R^{2}=.33, F(1,276)=134.740, p<.01\right)$. Selfjudgment entered secondly accounting for an additional $10 \%$ variance $\left(R^{2}=.43, \Delta R^{2}=.10\right.$, adjusted $R^{2}=.43, F(2,275)=$ 105.037, $p<.01)$. Over-identification entered thirdly, accounting for an additional $2 \%$ variance $\left(R^{2}=.45, \Delta R^{2}=.02\right.$, adjusted $\left.R^{2}=.44, F(3,274)=73.845, p<.01\right)$. Mindfulness entered fourthly accounting for an additional $1 \%$ variance 
$\left(\mathrm{R}^{2}=.46, \Delta \mathrm{R}^{2}=.01\right.$, adjusted $\mathrm{R}^{2}=.45, F(4,273)=57.375$, $p<.01)$. Isolation entered last, accounting for an additional $1 \%$ variance $\left(R^{2}=.47, \Delta R^{2}=.01\right.$, adjusted $R^{2}=.46, F(5,272)=$ $47.226, p<.01)$. Despite the initial regression design included mindfulness, common humanity, self-kindness, overidentification, isolation, and self-judgment as independent variables, the last regression model involved mindfulness, self-kindness, over-identification, isolation, and selfjudgment as predictors of flourishing and accounted for $47 \%$ of the variance. The standardized beta coefficients indicated the relative influence of the variables in last model with self-kindness $(\beta=.29, p<.01)$, self-judgment $(\beta=-.16$, $p<.01)$, over-identification $(\beta=-.13, p<.01)$, mindfulness $(\beta=$ $.15, p<.01)$, and isolation $(\beta=-.14, p<.01)$ all significantly influencing flourishing and self-kindness was the strongest predictor.

Table 2. Summary of regression analysis for variable predicting flourishing

\begin{tabular}{|c|c|c|c|c|c|}
\hline Model & Variables & $B$ & $\begin{array}{c}\text { Standard } \\
\text { Error of B }\end{array}$ & $\beta$ & $t$ \\
\hline \multirow{3}{*}{ Model 1} & Constant & 29,07 & 1.28 & & $22.76 * * *$ \\
\hline & Self-kindness & .99 & .09 & .57 & $11.61 * * *$ \\
\hline & Constant & 40,21 & 1.95 & & $20.58^{* * *}$ \\
\hline \multirow[t]{3}{*}{ Model 2} & Self-kindness & .70 & .09 & .41 & $7.93^{* * *}$ \\
\hline & Self-judgment & -.58 & .08 & -.37 & $-7.14 * * *$ \\
\hline & Constant & 41,88 & 2.04 & & $20.59 * * *$ \\
\hline \multirow{5}{*}{ Model 3} & Self-kindness & .67 & .09 & .39 & $7.58 * * *$ \\
\hline & Self-judgment & -.43 & .10 & -.27 & $-4.33 * * *$ \\
\hline & Over-iden. & -.29 & .11 & -.16 & $-2.63 * * *$ \\
\hline & Constant & 39,77 & 2.23 & & $17.78^{* * *}$ \\
\hline & Self-kindness & .53 & .11 & .30 & $4.81 * * *$ \\
\hline \multirow[t]{5}{*}{ Model 4} & Self-judgment & -.39 & .10 & -.25 & $-3.91 * * *$ \\
\hline & Over-iden. & -.26 & .11 & -.15 & $-2.45 * *$ \\
\hline & Mindfulness & .29 & .13 & .14 & $2.20 * *$ \\
\hline & Constant & 40,83 & 2.29 & & $17.86^{* * *}$ \\
\hline & Self-kindness & .49 & .11 & .29 & $4.49 * * *$ \\
\hline \multirow{4}{*}{ Model 5} & Self-judgment & -.26 & .12 & -.16 & $-2.22^{*}$ \\
\hline & Over-iden. & -.23 & .11 & -.13 & $-2.12^{*}$ \\
\hline & Mindfulness & .30 & .13 & .15 & $2.28^{*}$ \\
\hline & Isolation & -.25 & .12 & -.14 & $-2.01 *$ \\
\hline
\end{tabular}

\section{Discussion}

The purpose of the present research is to investigate the predictive role of self-compassion on flourishing and findings showed that there are significant relationships between these two variables. As expected self-kindness and mindfulness -adaptive dimensions of self-compassion- predicted flourishing positively and self-judgment, over-identification, and isolation -maladaptive dimensions of self-compassionpredicted flourishing negatively. However, awareness of common humanity did not emerge as significant predictor in the regression model. Also proportions of variance explained were relatively low which shows that there may be a need for including more psychosocial constructs to predict flourishing. Moreover in regression analysis self-kindness was found as the strongest predictor of flourishing and this may be due to the nature of self-kindness. Since selfkindness involves actively soothing and comforting oneself in times of distress (Gilbert, Baldwin, Irons, Baccus, \& Palmer, 2006) and has been found associated with higher levels of brain activation in the left prefrontal cortex which related to joy and optimism (Lutz, Greischar, Rawlings, Ricard, \& Davidson, 2004) it may contribute to the development of the feelings of flourishing.

In interpreting results of the present research, several plausible explanations exist. These findings are in line with the research that has shown that flourishing is closely associated with the indices of psychological adjustment such as environmental control, personal development, positive relations with others, life purposes (Telef, 2011), positive emotional reactivity (Catalino \& Fredrickson, 2011), competency, relatedness, autonomy, and self-acceptance (Diener et al., 2010). Findings of the present study are also consistent with the literature which demonstrated that self-kindness and mindfulness are related to the psychological strengths such as optimism, positive affect, life satisfaction, extraversion, agreeableness (Neff, Kirkpatrick, \& Rude, 2007), and psychological well-being (Akın, 2008a).

Second self-kindness and mindfulness have been found linked to feelings of autonomy and competence (Neff, 2003a), higher levels of brain activation in the left prefrontal cortex, a region associated with joy and optimism (Lutz et al., 2004), and they help to maintain optimistic expectations about the future (Scheier, Carver, \& Bridges, 1994). Thus results of the present research which demonstrated that high level of self-kindness and mindfulness related and predict to flourishing are quite understandable. Third individuals with self-kindness and mindfulness can deal with numerous difficult life events successfully and can experience more positive and less negative emotions, by behaving themselves with care and gentle and not allowing themselves to be swept up by negative emotions (Neff, 2003a). They do not need to rely on illusions or defensiveness and have a clear perception of their characteristics, both good and bad. This provide them to have more accurate self-perceptions and selfappraisals (i.e., without self-enhancement or selfdeprecation) than those lacking (Leary et al., 2007). Similarly since flourishing is related to (and also facilitate) feelings of wellness, resilience (Fredrickson \& Losada, 2005; Larsen \& Prizmic, 2008), and a balance between positive and negative affect (Diehl et al., 2011), that people experience when they are self-compassionate (Neff, Kirkpatrick, \& Rude, 2007) flourishing and self-compassion may seem alike in nature and the positive associations between self-kindness, mindfulness, and flourishing are not surprising.

Also as hypothesized self-judgment, isolation, and overidentification -maladaptive dimension of self-compassionpredicted flourishing in a negative way. People with selfjudgment, isolation, and over-identification, ruminate their own limitations (Barnard \& Curry, 2011; Neff, Kirkpatrick, \& Rude, 2007), become identified with and carried away by negative feelings and thoughts towards themselves (Neff \& 
Vonk, 2009), reject their own feelings and thoughts, feel ashamed from their failures (Neff, 2003a), and are often exposed to psychological problems (Nolen-Hoeksema, 1991). Therefore, these dimensions of self-compassion are maladaptive and so these individuals may feel lower levels of sense of flourishing.

Besides, significant correlations were found between dimensions of self-compassion. This result is not interesting since they interact so as to mutually enhance and engender one another (Neff, 2003a). For instance, if individuals accept and tolerate their distressful experiences (high mindfulness) and if they are kind toward themselves (high self-kindness), they may avoid suppressing these experiences (high mindfulness). Therefore, when they are aware that these negative experiences are something that all humans experience (high awareness of common humanity), they are not trapped by over-identification (high mindfulness) (Neff, Hsieh, \& Dejitterat, 2005).

Limitations of the study should be acknowledged. First of all, perhaps the most important limitation is that the results obtained in this study should not be generalized neither to all university students nor to other student populations, since the data were collected in Sakarya and Kocaeli Universities, Turkey. Therefore further study is required to assess the relationships between self-compassion and flourishing

\section{References}

Akın, A. (2008a). Scales of Psychological Well-being: A study of validity and reliability. Educational Science: Theory \& Practice, 8(3), 721-750.

Akin, A. (2008b). Self-compassion and achievement goals: A structural equation modeling approach. Eurasian Journal of Educational Research, 31, 1-15.

Akın, A. (2009). Self-compassion and submissive behavior. Education and Science, 34(152), 138-147.

Akin, A. (2010a). Self-compassion and interpersonal cognitive distortions. Hacettepe University Journal of Education, 39, 1-9.

Akın, A. (2010b). Self-compassion and loneliness. International Online Journal of Educational Sciences (IOJES), 2(3), 702-718.

Akın, A. (2012). Self-compassion and automatic thoughts. Hacettepe University Journal of Education, 42(1), 1-10.

Akin, A., \& Eroglu, Y. (2013). Self-compassion and relationalinterdependent self-construal. Studia Psychologica, 55(2), 111-121.

Akin, A., \& Fidan, M. (2012, April). The validity and reliability of the Turkish version of the Flourishing Scale. Paper presented at the $3^{\text {rd }}$ International Conference on New Trends in Education and their Implications (ICONTE-2012), April, 26-28, Antalya, Turkey.

Akın, Ü., Akin, A., \& Abac1, R. (2007). Self-compassion Scale: The study of validity and reliability. Hacettepe University Journal of Education, 33, 1-10.

Akın, A., Kayış, A. R., \& Satıcı, S. A. (2011). Self-compassion and social support. Paper presented at the International Conference on New Trends in Education and their Implications (ICONTE-2011), April, 27-29, Antalya, Turkey.

Baer, R. A., Smith, G. T., \& Allen, K. B. (2004). Assessment of mindfulness by self-report: The Kentucky inventory of mindfulness skills. Assessment, 11, 191-206.

Baker, L., \& McNulty, J. K. (2011). Self-compassion and relationship maintenance: The moderating roles of conscientiousness and gender. Journal of Personality and Social Psychology, 100, 853-873.

Barnard, L. K., \& Curry, J. F. (2011). Self-compassion: Conceptualizations, correlates, \& interventions. Review of General Psychology, 15(4), 289-303.

Catalino, L. I., \& Fredrickson, B. L. (2011). A Tuesday in the life of a flourisher: The role of positive emotional reactivity in optimal mental health. Emotion, 11(4), 938-950. that targeting other populations to generate more solid relationships among the constructs examined in this study. Secondly, as correlational statistics were utilized, no definitive statements can be made about causality. Thirdly, the data reported here for self-compassion and flourishing are limited to self-reported data and did not use a qualitative measure of these variables. And last, the test-retest reliability coefficients for the Self-compassion Scale did not meet the accepted standard of 7 or over (Field, 2005).

Consequently, the present research provides important information about the predictors of flourishing. An increment in mindfulness and self-kindness will increase flourishing. In contrary an increment in self-judgment, overidentification, and isolation will decrease flourishing. This research also suggests that the encouragement of selfcompassion could be highly beneficial for flourishing. Additionally, encouraging the development of self-compassion should be useful individuals by helping them to counter destructive self-critical tendencies and deal with their negative emotions with greater clarity and equanimity (Neff, 2003a). Clearly, however, more research needs to be done to understand how self-compassion is linked to functioning. Future research should also consider other individual differences that may moderate the relationships of self-compassion with flourishing.

Diehl, M., Hay, E. L., \& Berg, K. M. (2011). The ratio between positive and negative affect and flourishing mental health across adulthood. Aging \& Mental Health, 15, 882-893.

Diener, E., Wirtz, D., Tov, W., Kim-Prieto, C., Choi, D. W., Oishi, S., \& Biswas-Diener, R. (2010). New well-being measures: Short scales to assess flourishing and positive and negative feelings. Social Indicator Research, 97, 143-156.

Field, A. (2005). Discovering statistics using SPSS (2nd ed.). London: Sage Publications.

Forgeard, M. J. C., Jayawickreme, E., Kern, M., \& Seligman, M. E. P. (2011). Doing the right thing: Measuring wellbeing for public policy. International Journal of Wellbeing, 1(1), 79-106.

Fredrickson, B. L., \& Losada, M. F. (2005). Positive affect and the complex dynamics of human flourishing. American Psychologist, 60, 678-686.

Gilbert, P. (2005). Social mentalities: A bio-psycho-social and evolutionary reflection on social relationships. In M. W. Baldwin (Ed.), Interpersonal cognition (pp. 299-335). New York: Guilford.

Gilbert, P., Baldwin, M. W., Irons, C., Baccus, J. R., \& Palmer, M. (2006). Self-criticism and self-warmth: An imagery study exploring their relation to depression. Journal of Cognitive Psychotherapy, 20, 183-200.

Gokcen, N., Hefferon, K., \& Attree, E., (2012). University students' constructions of 'flourishing' in British higher education: An inductive content analysis. International Journal of Wellbeing, 2(1), 1-21.

Gunaratana, V. H. (1993). Sati. In mindfulness in plain English. Somerville, MA: Wisdom Publications.

Huppert, F. A. (2009). Psychological well-being: Evidence regarding its causes and consequences. Applied Psychology: Health and Well-Being, 1(2), 137-164.

Huppert, F. A. \& So, T. T. C. (2009). What percentage of people in Europe are flourishing and what characterizes them? Measuring subjective wellbeing: An opportunity for NGOs? OECD/ISQOLS meeting, Florence, Italy, 23-24 July.

İskender, M., \& Akın, A. (2010). Social self-efficacy, academic locus of control, and internet addiction. Computers \& Education, 54(4), 1101-1106.

Keyes, C. L. M. (2002). The mental health continuum: From languishing to flourishing in life. Journal of Health and Behavior Research, 43, 207-222. 
Keyes, C. L. M. (2005). Mental health and/or mental illness? Investigating axioms of the complete state model of health. Journal of Consulting and Clinical Psychology, 73, 539-548.

Keyes, C. L. M. (2007). Promoting and protecting mental health as flourishing: A complementary strategy for improving national mental health. American Psychologist, 62, 95-108.

Larsen, R. J., \& Prizmic, Z. (2008). Regulation of emotional well-being: Overcoming the hedonic treatmill. In M. Eid \& R. J. Larsen (Eds.). The science of subjective well-being (pp. 258-289). New York: Guilford Press.

Leary, M. R., Tate, E. B., Adams, C. E., Allen, A. B., \& Hancock, J. (2007). Self-compassion and reactions to unpleasant self-relevant events: The implications of treating oneself kindly. Journal of Personality and Social Psychology, 92, 887-904.

Lutz, A., Greischar, L. L., Rawlings, N. B., Ricard, M., \& Davidson, R. J. (2004). Long-term meditators self-induce high-amplitude gamma synchrony during mental practice. Proceedings of the National Academy of Sciences, 101, 16369-16373.

Martin, J. R. (1997). Mindfulness: A proposed common factor. Journal of Psychotherapy Integration, 7, 291-312.

Michalec, B., Keyes, C. L. M., \& Nalkur, S. (2009). Flourishing. In S. J. Lopez (Ed), The Encyclopedia of Positive Psychology (pp. 391-394). West Sussex: Wiley-Blackwell.

Neff, K. D. (2003a). Self-compassion: An alternative conceptualization of a healthy attitude toward oneself. Self and Identity, 2(2), 85-102.

Neff, K. D. (2003b). The development and validation of a scale to measure self-compassion. Self and Identity, 2(3), 223-250.

Neff, K. D. (2009). Self-compassion. In M. R. Leary \& R. H. Hoyle (Eds.). Handbook of individual differences in social behavior (pp. 561-573). Guilford Press.

Neff, K. D., Hsieh, Y., \& Dejitterat, K. (2005). Self-compassion, achievement goals, and coping with academic failure. Self and Identity, 4, 263287.

Neff, K. D., Kirkpatrick, K. L., \& Rude, S. S. (2007). Self-compassion and adaptive psychological functioning. Journal of Research in Personality, 41, 139-154.

Neff, K. D., Rude, S. S., \& Kirkpatrick, K. L. (2007). An examination of self-compassion in relation to positive psychological functioning and personality traits. Journal of Research in Personality, 41, 908-916.
Neff, K. D., \& Vonk, R. (2009): Self-compassion versus global self-esteem: Two different ways of relating to oneself. Journal of Personality, 77, 23 50.

Nisker, W. (1998). Mindfulness: The opposable thumb of consciousness (Chapter 3). In Buddha's nature: A practical guide to discovering your place in the cosmos (pp. 26-30). New York: Bantam Books.

Nolen-Hoeksema, S. (1991). Responses to depression and their effects on the duration of depressive episodes. Journal of Abnormal Psychology, 100, 569-582

Ramones, S. M. (2011). Unleashing the power: Anthony Robbins, positive psychology, and the quest for human flourishing. Capstone Project, Master of Applied Positive Psychology, University of Pennsylvania.

Rosenberg, L. (1999). Breathing with the body (Chapter 1). In Breath by breath: The liberating practice of insight meditation (pp. 10-39). Boston: Shambala.

Scheier, M. F., Carver, C. S., \& Bridges, M. W. (1994). Distinguishing optimism from neuroticism (and trait anxiety, self-mastery, and selfesteem): A re-evaluation of the Life Orientation Test. Journal of Personality and Social Psychology, 67, 1063-1078.

Schroevers, M. J., \& Brandsma, R. (2010). Is learning mindfulness associated with improved affect after mindfulness-based cognitive therapy? British Journal of Psychology, 101, 95-107.

Segal, Z. V., Williams, J. M. G., \& Teasdale, J. D. (2002). Mindfulness-based cognitive therapy for depression. New York: Guilford.

Seligman, M. E. P. (2011). Flourish. New York City: Simon and Schuster.

Shapiro, S., Oman, D., Thoresen, C., Plante, T., \& Flinders, T. (2008). Cultivating mindfulness: Effects on well-being. Journal of Clinical Psychology, 64, 840-862.

Tabachnick, B. G., \& Fidell, L. S. (2001). Using multivariate statistics. Boston: Allyn and Bacon.

Telef, B. B. (2011). The validity and reliability of the Turkish version of the Psychological Well-being Scale. Paper presented at the 11th National Congress of Counseling and Guidance, October, 3-5, Izmir, Turkey.

Werner, K. H., Jazaieri, H., Goldin, P. R., Ziv, M., Heimberg, R. G., \& Gross, J. J. (2012). Self-compassion and social anxiety disorder. Anxiety, Stress, and Coping, 25(5), 543-558.

(Article received: 05-02-2014; revised: 21-07-2014; accepted: 21-08-2014) 